\title{
Expiratory flow limitation relates to symptoms during COPD exacerbations requiring hospital admission
}

This article was published in the following Dove Press journal:

International Journal of COPD

14 May 2015

Number of times this article has been viewed

\author{
Kanika Jetmalani $i^{1,2}$ \\ Sophie Timmins 1,3,4 $^{1,4}$ \\ Nathan J Brown ${ }^{1,4}$ \\ Chantale Diba ${ }^{1,4}$ \\ Norbert Berend ${ }^{1,4,5}$ \\ Cheryl M Salome $e^{1,2,4}$ \\ Fu-Qiang Wen ${ }^{6}$ \\ Peng Chen ${ }^{6}$ \\ Gregory G King ${ }^{1-4}$ \\ Claude S Farah ${ }^{1,2,7}$ \\ 'Woolcock Institute of Medical \\ Research, ${ }^{2}$ Sydney Medical School, \\ University of Sydney, ${ }^{3}$ Department \\ of Respiratory Medicine, Royal \\ North Shore Hospital, ${ }^{4}$ Cooperative \\ Research Centre for Asthma and \\ Airways, ${ }^{5}$ Department of Respiratory \\ Research, George Institute of Global \\ Health, Sydney, NSW, Australia; \\ ${ }^{6}$ Department of Medicine, West \\ China Hospital, West China School \\ of Medicine, Sichuan University, \\ Chengdu, People's Republic of China; \\ ${ }^{7}$ Department of Respiratory Medicine, \\ Concord Hospital, Sydney, NSW, \\ Australia
}

Background: Expiratory flow limitation (EFL) is seen in some patients presenting with a COPD exacerbation; however, it is unclear how EFL relates to the clinical features of the exacerbation. We hypothesized that EFL when present contributes to symptoms and duration of recovery during a COPD exacerbation. Our aim was to compare changes in EFL with symptoms in subjects with and without flow-limited breathing admitted for a COPD exacerbation.

Subjects and methods: A total of 29 subjects with COPD were recruited within 48 hours of admission to West China Hospital for an acute exacerbation. Daily measurements of postbronchodilator spirometry, resistance, and reactance using the forced oscillation technique and symptom (Borg) scores until discharge were made. Flow-limited breathing was defined as the difference between inspiratory and expiratory respiratory system reactance (EFL index) greater than $2.8 \mathrm{cmH}_{2} \mathrm{O} \cdot \mathrm{s} \cdot \mathrm{L}^{-1}$. The physiological predictors of symptoms during recovery were determined by mixed-effect analysis.

Results: Nine subjects (31\%) had flow-limited breathing on admission despite similar spirometry compared to subjects without flow-limited breathing. Spirometry and resistance measures did not change between enrolment and discharge. EFL index values improved in subjects with flowlimited breathing on admission, with resolution in four patients. In subjects with flow-limited breathing on admission, symptoms were related to inspiratory resistance and EFL index values. In subjects without flow-limited breathing, symptoms related to forced expiratory volume in 1 second/forced vital capacity. In the whole cohort, EFL index values at admission was related to duration of stay $(R s=0.4, P=0.03)$.

Conclusion: The presence of flow-limited breathing as well as abnormal respiratory system mechanics contribute independently to symptoms during COPD exacerbations.

Keywords: COPD, exacerbations, flow limitation, respiratory mechanics, symptoms

\section{Introduction}

Chronic obstructive pulmonary disease (COPD) is heterogeneous in terms of mechanics, prognosis, and exacerbation risks. ${ }^{1}$ Exacerbations are associated with significant patient morbidity and health-resource utilization. The clinical course of COPD exacerbations is heterogeneous, with patients reporting a wide range of symptoms and changes in spirometric measurements. ${ }^{2,3}$ Expiratory flow limitation (EFL) during tidal breathing occurs during acute COPD exacerbations, and when present, flow cannot be increased further by increased respiratory effort. EFL occurs in $40 \%{ }^{4}$ to $94 \% \%^{5}$ of patients admitted to hospital for a COPD exacerbation and resolves in about half of those patients at discharge. ${ }^{4}$ EFL may account for some of the clinical heterogeneity of COPD exacerbations, ${ }^{2}$ although the clinical significance of EFL in terms of symptoms during COPD exacerbations is poorly understood.
Correspondence: Kanika Jetmalani Woolcock Institute of Medical Research, 43I Glebe Point Road, Glebe, Sydney, NSW 2037, Australia

Email kanika.jetmalani@sydney.edu.au 
One way to measure EFL is by the forced oscillation technique (FOT). FOT involves superimposition of an oscillatory pressure signal during tidal breathing, from which resistance and reactance are derived as measures of airway caliber and oscillatory stiffness of the respiratory system, respectively. Reactance is sensitive to regional airway closure and narrowing when ventilation across different lung regions becomes more heterogeneous. Reactance decreases during expiration, indicating greater oscillatory stiffness, due to airway narrowing. However, with greater expiratory airway narrowing and ultimately the development of flow-limiting segments due to expiratory airway collapse, reactance decreases further in expiration, leading to a greater difference between expiratory and inspiration. ${ }^{6}$ When the difference in reactance between inhalation and exhalation exceeds $2.8 \mathrm{cmH}_{2} \mathrm{O} \cdot \mathrm{s} \cdot \mathrm{L}^{-1}$, EFL is present during every tidal breath. ${ }^{7,8}$ EFL measured by this FOT index (EFL index) improves at 1 and 6 weeks after the onset of COPD exacerbations, ${ }^{5}$ although no relationships with clinical parameters have been previously reported.

The presence of flow-limited breathing and variations in EFL index values may account for some of the changes in dyspnea during the resolution of severe COPD exacerbations. ${ }^{9}$ Therefore, resolution of EFL with a decrease in EFL index values may relate to improvements in symptoms during recovery from an exacerbation. We hypothesized that EFL when present contributes to symptoms and duration of recovery during a COPD exacerbation. Our aim was to compare changes in EFL index values measured by FOT, with symptoms of dyspnea measured by the Borg score, in subjects with and without flow-limited breathing (EFL index $\left.>2.8 \mathrm{cmH}_{2} \mathrm{O} \cdot \mathrm{s} \cdot \mathrm{L}^{-1}\right)$ at the time of hospital admission for a COPD exacerbation.

\section{Subjects and methods Patients}

Patients hospitalized for an acute COPD exacerbation at West China Hospital were approached to take part in the study. Patients over 40 years old with a physician diagnosis of COPD, a smoking history $>10$ pack-years, and postbronchodilator forced expiratory volume in 1 second $\left(\mathrm{FEV}_{1}\right)$ / forced vital capacity $(\mathrm{FVC})<0.7$ were recruited within 48 hours of admission. Exclusion criteria were the presence of respiratory failure requiring intubation or nasal ventilation, pneumonia as defined radiologically, admission for COPD exacerbation within the previous 8 weeks, pleural disease, any active cardiac disease, inability to perform the lungfunction tests required in this study, and inability to provide written informed consent. The GOLD (Global initiative for chronic Obstructive Lung Disease) definition for acute exacerbations was used. ${ }^{10}$ Written informed consent was obtained from all participants. The human research ethics committee of West China Hospital granted study approval (2009017).

\section{Study design}

This was a prospective observational study of patients admitted to hospital for an acute exacerbation of COPD. Consecutive patients admitted to the Respiratory Department for acute COPD exacerbations were approached for study participation. Every subject underwent the following measurements at the same time every day until hospital discharge: patient-rated dyspnea intensity using the Borg scale $^{11}$ and postbronchodilator FOT followed by spirometry. Patients were managed as usual by their clinical teams without knowledge of study measurements. Patients were discharged based on the attending physician's usual clinical criteria for discharge. Predictors of dyspnea and duration of admission were examined for subjects separated by an EFL index value greater or less than $2.8 \mathrm{cmH}_{2} \mathrm{O} \cdot \mathrm{s} \cdot \mathrm{L}^{-1}$.

\section{Physiological measurements}

Spirometry (Jaeger ${ }^{\circledR}$ MasterScreen ${ }^{\text {TM }}$ PFT; CareFusion, San Diego, CA, USA) was performed according to American Thoracic Society/European Respiratory Society guidelines. ${ }^{12}$ Values are reported as percentage of that predicted..$^{13}$

Respiratory system impedance was measured at an oscillation frequency of $6 \mathrm{~Hz}$ using an in-house-built FOT device. ${ }^{14}$ Flow was measured using a screen-type pneumotachograph (3100 series, flow range $0-160 \mathrm{~L} \cdot \mathrm{min}^{-1}$; Hans Rudolph, Shawnee Mission, KS, USA). Impedance parameters were calculated as averages from three 60 -second, technically satisfactory recordings, based on the quality-control method of Robinson et al. ${ }^{15}$ Complete breaths were examined separately, and breaths that had extreme and negative mean respiratory system resistance (Rrs) values or artifacts due to occlusions or leaks were excluded. A minimum of three technically satisfactory breaths per recording were required from at least two recordings. The mean values from those recordings were used for analyses. Impedance parameters determined were Rrs, Rrs during inspiration $\left(\operatorname{Rrs}_{\text {insp }}\right)$, Rrs during expiration ( $\operatorname{Rrs}_{\text {exp }}$ ), mean respiratory system reactance (Xrs), Xrs during inspiration ( $\mathrm{Xrs}_{\text {insp }}$ ), and Xrs during expiration $\left(\mathrm{Xrs}_{\text {exp }}\right)$.

The expiratory flow-limitation index $\Delta \mathrm{Xrs}$ was calculated as the mean difference between $\mathrm{Xrs}_{\text {insp }}$ and $\mathrm{Xrs}_{\text {exp }}\left(\mathrm{Xrs}_{\text {insp }}\right.$ $\mathrm{Xrs}_{\text {exp }}$ ), as previously described. ${ }^{6}$ The index was used as a continuous variable for analyzing correlations. A threshold 
$\left(2.8 \mathrm{cmH}_{2} \mathrm{O} \cdot \mathrm{s} \cdot \mathrm{L}^{-1}\right)^{5}$ was used to group patients into those with and without EFL.

\section{Statistical analysis}

Data were analyzed using SAS Enterprise Guide version 4.3 (SAS Institute, Cary, NC, USA). Data are expressed as means and standard deviations unless otherwise stated. Wilcoxon matched (paired) signed-rank tests and Mann-Whitney $U$-tests were used to compare parameters within and between patients with and without EFL on admission. Correlations were assessed using the Spearman coefficient for nonparametric variables and the Pearson coefficient for parametric variables. A mixed-effect model was performed to determine the day-to-day changes in EFL index values throughout the hospital stay, and to determine the physiological predictors of dyspnea (Borg score) throughout the hospital stay. Separate models were run for patients with an EFL index value of $2.8 \mathrm{cmH}_{2} \mathrm{O} \cdot \mathrm{s} \cdot \mathrm{L}^{-1}$ or greater, and less than $2.8 \mathrm{cmH}_{2} \mathrm{O} \cdot \mathrm{s} \cdot \mathrm{L}^{-1}$. $P<0.05$ was considered statistically significant.

\section{Results}

A total of 41 subjects with COPD were approached to take part in the study; 35 subjects consented, but six subjects were excluded (four had technical difficulties/discomfort in completing maneuvers, and two had less than 3 days' worth of data), resulting in 29 subjects' data being available for analyses. All but two subjects were recruited within 24 hours of admission. All subjects were current smokers. Baseline demographics of all subjects on study enrollment are shown in Table 1. All subjects were taking short-acting bronchodilators as required, and eight were taking longacting bronchodilators.

All subjects were treated with terbutaline, budesonide, and oral corticosteroids during the admission. Spirometry

Table I Baseline characteristics of COPD patients at hospital admission

\begin{tabular}{ll}
\hline Total (males) & $29(22)$ \\
Age (years) & $63(8.3)$ \\
BMI $\left(\mathrm{kg} / \mathrm{m}^{2}\right)$ & $23.2(3.5)$ \\
Smoking history (years) & $54.2(23.5)$ \\
Duration of admission (days) & $5(\mathrm{I})$ \\
$\mathrm{FEV}_{1}(\mathrm{~L})$ & $0.76(0.3 \mathrm{I})$ \\
$\mathrm{FEV}_{1}(\%$ predicted) & $31.03(\mathrm{I} 2.7)$ \\
FVC (L) & $1.7(0.5)$ \\
FVC (\% predicted) & $56.2(\mathrm{I} 5.2)$ \\
FEV $/$ FVC & $0.44(0.1)$ \\
\hline
\end{tabular}

Note: Data presented as mean (standard deviation) unless otherwise stated. Abbreviations: BMI, body mass index; $\mathrm{FEV}_{1}$, forced expiratory volume in I second; FVC, forced vital capacity; COPD, Chronic obstructive pulmonary disease. did not change between study enrollment to discharge. Changes in Rrs and Xrs were $-0.56 \mathrm{cmH}_{2} \mathrm{O} \cdot \mathrm{s} \cdot \mathrm{L}^{-1}(P=0.15)$ and $0.83 \mathrm{cmH} \mathrm{C}_{2} \mathrm{O} \cdot \mathrm{s} \cdot \mathrm{L}^{-1}(P=0.047)$ between study enrollment to discharge. Changes in $\operatorname{Rrs}_{\text {insp }}, \mathrm{Rrs}_{\text {exp }}, \mathrm{Xrs}_{\text {insp }}$, and $\mathrm{Xrs}_{\exp }$ were $-0.42 \mathrm{cmH}_{2} \mathrm{O} \cdot \mathrm{s} \cdot \mathrm{L}^{-1}(P=0.17),-0.54 \mathrm{cmH}_{2} \mathrm{O} \cdot \mathrm{s} \cdot \mathrm{L}^{-1}$ $(P=0.17), 0.09 \mathrm{cmH}_{2} \mathrm{O} \cdot \mathrm{s} \cdot \mathrm{L}^{-1}(P=0.63)$, and $1.04 \mathrm{cmH}_{2} \mathrm{O} \cdot \mathrm{s} \cdot \mathrm{L}^{-1}$ $(P=0.02)$, respectively.

At study entry, nine subjects (31\%) had EFL during resting tidal breathing. The two subjects that were recruited within 24-48 hours did not have flow-limited breathing at study entry. EFL index values decreased from study enrolment $\left(2.46 \mathrm{cmH}_{2} \mathrm{O} \cdot \mathrm{s} \cdot \mathrm{L}^{-1}\right)$ to hospital discharge $\left(1.51 \mathrm{cmH}_{2} \mathrm{O} \cdot \mathrm{s} \cdot \mathrm{L}^{-1}\right)$ $(P=0.006)$. EFL index values on admission were related to the duration of admission $(R s=0.4, P=0.03)$, ie, the more severe the EFL, the longer duration of admission. EFL index values were not related to the Borg score at study enrolment $(R s=0.2, P=0.30)$. EFL index values on admission correlated with $\operatorname{Rrs}(R s=0.66, P=0.001), \operatorname{Rrs}_{\text {insp }}(R s=0.64, P=0.001)$, and $\operatorname{Rrs}_{\exp }(R s=0.68, P=0.001)$ at admission. EFL index values unrelated to any spirometry indices.

\section{Comparisons between groups with EFL and no EFL on admission}

Table 2 shows the group results for spirometry, respiratory system mechanics, and symptom (Borg) scores at admission and discharge in subjects in whom EFL was present or absent on admission. There were no differences in age, smoking history, body mass index, or duration of hospital stay between the groups. On admission, spirometry and dyspnea intensity were similar between the EFL groups. However, subjects who had EFL had higher Rrs insp $_{\text {and }}$ ars ${ }_{\text {exp }}$ and lower Xrs ${ }_{\text {insp }}$ and $\mathrm{Xrs}_{\text {exp }}$ compared to subjects who did not have EFL.

The improvement in dyspnea score during the hospital admission was similar between the two groups. Spirometry was unchanged between study enrollment and discharge. Rrs was unchanged between study enrollment and discharge, with between-group differences in Rrs remaining at discharge. Xrs improved (increased) during the study period in the subjects who had EFL on admission. There were no changes in Xrs in subjects who did not have EFL on admission. The increase in Xrs was greater in subjects who had EFL so that $\mathrm{Xrs}_{\text {insp }}, \mathrm{Xrs}_{\text {exp }}$, and EFL index values were similar between groups at discharge. The largest improvement was in $\mathrm{Xrs}_{\text {exp }}$, which led to a decrease in $\Delta \mathrm{Xrs}$ and subsequent resolution of EFL in some subjects. At discharge, flow limitation had resolved in four of the nine subjects with flow-limited breathing on admission. One subject with borderline flow limitation $\left(\Delta \mathrm{Xrs}=2.7 \mathrm{cmH}_{2} \mathrm{O} \cdot \mathrm{s} \cdot \mathrm{L}^{-1}\right)$ 
Table 2 Physiological measurements and symptom (Borg) scores at admission and discharge in COPD patients with and without EFL on admission

\begin{tabular}{|c|c|c|c|c|c|c|c|c|}
\hline & \multirow[t]{2}{*}{ Units } & \multicolumn{3}{|c|}{$\begin{array}{l}\text { EFL at admission } \\
(n=9)\end{array}$} & \multicolumn{3}{|c|}{$\begin{array}{l}\text { No EFL at admission } \\
(n=20)\end{array}$} & \multirow{2}{*}{$\begin{array}{l}\text { Between groups } \\
\text { (admission) } \\
P\end{array}$} \\
\hline & & Admission & Discharge & $P$ & Admission & Discharge & $P$ & \\
\hline $\mathrm{FEV}_{1}$ & $\mathrm{~L}$ & $0.69(0.31)$ & $0.74(0.18)$ & 0.5 & $0.78(0.33)$ & $0.82(0.38)$ & 0.6 & 0.4 \\
\hline FVC & L & $1.50(0.54)$ & $1.54(0.33)$ & 0.6 & $1.79(0.47)$ & $1.75(0.50)$ & 0.4 & 0.2 \\
\hline $\mathrm{FEV}_{1} / \mathrm{FVC}$ & & $0.46(0.10)$ & $0.48(0.09)$ & 0.5 & $0.43(0.09)$ & $0.46(0.10)$ & 0.4 & 0.5 \\
\hline Rrs & $\mathrm{cmH}_{2} \mathrm{O} \cdot \mathrm{s} \cdot \mathrm{L}^{-1}$ & $8.79(2.55)$ & $7.73(2.37)$ & 0.3 & $5.94(2.80)$ & $5.61(2.12)$ & 0.2 & 0.01 \\
\hline $\operatorname{Rrs}_{\text {insp }}$ & $\mathrm{cmH}_{2} \mathrm{O} \cdot \mathrm{s} \cdot \mathrm{L}^{-1}$ & $7.67(2.17)$ & 7.05 (1.75) & 0.2 & $5.67(2.67)$ & $5.34(\mathrm{I} .7 \mathrm{I})$ & 0.4 & 0.003 \\
\hline $\operatorname{Rrs}_{\text {exp }}$ & $\mathrm{cmH}_{2} \mathrm{O} \cdot \mathrm{s} \cdot \mathrm{L}^{-1}$ & $9.00(2.74)$ & $8.02(2.74)$ & 0.3 & $6.09(2.84)$ & $5.74(2.29)$ & 0.2 & 0.01 \\
\hline Xrs & $\mathrm{cmH}_{2} \mathrm{O} \cdot \mathrm{s} \cdot \mathrm{L}^{-1}$ & $-7.37(2.27)$ & $-4.4 \mid(1.92)$ & 0.008 & $-3.05(1.42)$ & $-3.19(1.72)$ & 0.5 & $<0.00$ I \\
\hline $\mathrm{Xrs}_{\text {insp }}$ & $\mathrm{cmH}_{2} \mathrm{O} \cdot \mathrm{s} \cdot \mathrm{L}^{-1}$ & $-3.73(0.79)$ & $-2.90(0.87)$ & 0.01 & $-2.22(0.93)$ & $-2.46(1.29)$ & 0.3 & 0.001 \\
\hline $\mathrm{Xrs}_{\exp }$ & $\mathrm{cmH}_{2} \mathrm{O} \cdot \mathrm{s} \cdot \mathrm{L}^{-1}$ & $-8.70(3.19)$ & $-5.12(2.33)$ & 0.008 & $-3.55(1.76)$ & $-3.66(2.00)$ & 0.5 & $<0.00$ I \\
\hline$\Delta \mathrm{Xrs}$ & $\mathrm{cmH}_{2} \mathrm{O} \cdot \mathrm{s} \cdot \mathrm{L}^{-1}$ & $4.97(2.64)$ & $2.2 \mathrm{I}(\mathrm{I} .5 \mathrm{I})$ & 0.008 & $1.32(1.03)$ & $1.19(0.98)$ & 0.3 & $<0.00 \mathrm{I}$ \\
\hline Borg & & 6.44 (1.01) & $4.83(1.87)$ & 0.01 & $6.11(1.00)$ & 4.55 (I.47) & 0.007 & 0.4 \\
\hline
\end{tabular}

Note: Data presented as mean (standard deviation).

Abbreviations: EFL, expiratory flow limitation (defined by EFL index $>2.8 \mathrm{cmH}_{2} \mathrm{O} \cdot \mathrm{s} \cdot \mathrm{L}^{-1}$ ); $\mathrm{FEV}$, forced expiratory volume in I second; FVC, forced vital capacity; Rrs, mean

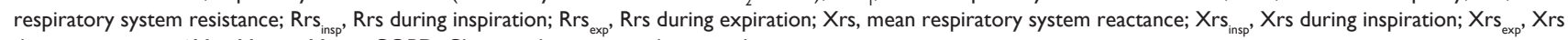
during expiration; $\Delta \mathrm{Xrs}, \mathrm{Xrs}_{\text {insp }}-\mathrm{Xrs}_{\text {exp }}$; COPD, Chronic obstructive pulmonary disease.

on admission did not improve, such that he was classified as flow-limited at discharge $\left(\Delta \mathrm{Xrs}=3.2 \mathrm{cmH}_{2} \mathrm{O} \cdot \mathrm{s} \cdot \mathrm{L}^{-1}\right)$.

\section{Relationships between symptoms and physiology during recovery}

Figure 1 shows the day-to-day changes in mean symptom (Borg) scores, $\mathrm{FEV}_{1} / \mathrm{FVC}, \mathrm{Rrs}_{\text {insp }}$, and $\triangle \mathrm{Xrs}$ in subjects with and without flow-limited breathing on admission. In subjects with flow limitation, most of the improvements in EFL index values and respiratory mechanics occurred in the first 24 hours of the study.

Separate mixed-effect models were run for subjects with and without flow-limited breathing on admission to determine the predictors of daily Borg scores, with daily $\mathrm{FEV}_{\mathrm{l}} /$ $\mathrm{FVC}, \mathrm{FVC}, \mathrm{Rrs}_{\mathrm{insp}}$, and $\Delta \mathrm{Xrs}$ as independent predictors. In subjects with flow limitation on admission, the independent predictors of Borg score were $\Delta \mathrm{Xrs}$ and $\operatorname{Rrs}_{\text {insp }}$. The greater the decrease in $\Delta \mathrm{Xrs}$, the greater the reduction in breathlessness. Unexpectedly, for a greater decrease in $\operatorname{Rrs}_{\text {insp }}$, the less the reduction in breathless. In subjects without flow limitation on admission, $\mathrm{FEV}_{1} / \mathrm{FVC}$ was the only independent predictor of Borg score (Table 3).

\section{Discussion}

In this study of COPD exacerbations, we found that when EFL was present, decrease in EFL index values was associated with improvement in dyspnea, as measured by the Borg score. In contrast, when EFL was absent at the start of the exacerbation, dyspnea was predicted by the $\mathrm{FEV}_{1} / \mathrm{FVC}$ ratio. It is clear from this study and others ${ }^{4}$ that not all patients with COPD have flow-limited breathing during exacerbations, but in those who do, EFL is an important contributor to symptoms.

This study indicates that reactance and flow limitation improve early in the recovery phase of a COPD exacerbation in those who have flow-limited breathing, whereas resistance and spirometry do not change. Previous studies have reported improvement in reactance 1 week after hospital admission. ${ }^{4,5}$ Using a different method to calculate flow limitation, one study reported improvements at 1 and 6 weeks after admission, ${ }^{5}$ while in another study flow limitation did not change. ${ }^{4}$ Other physiological improvements at 1 week after admission have been found by changes in respiratory frequency and in slow $\mathrm{VC}$ without associated $\mathrm{FEV}_{1}$, FVC, or static lung-volume changes. ${ }^{16}$ The mechanisms by which Xrs and EFL improve are unknown, but speculatively they could include improvements in airway smooth-muscle contraction, in intrabronchial sputum, and airway-wall inflammation. ${ }^{17}$ Such changes could reduce expiratory collapse and consequently reduce airway closure and EFL.

The presence of flow-limited breathing during a COPD exacerbation has potential clinical implications. It is possible that the EFL index value at the time of admission for an exacerbation may signal more severe physiological perturbations that are not detectable by spirometry, since increased EFL index values at admission correlated with longer hospital stays. Furthermore, patients with flow-limited breathing on admission (EFL index values greater than $\left.2.8 \mathrm{cmH}_{2} \mathrm{O} \cdot \mathrm{s} \cdot \mathrm{L}^{-1}\right)$, improvement in $\mathrm{EFL}$ index values was a 

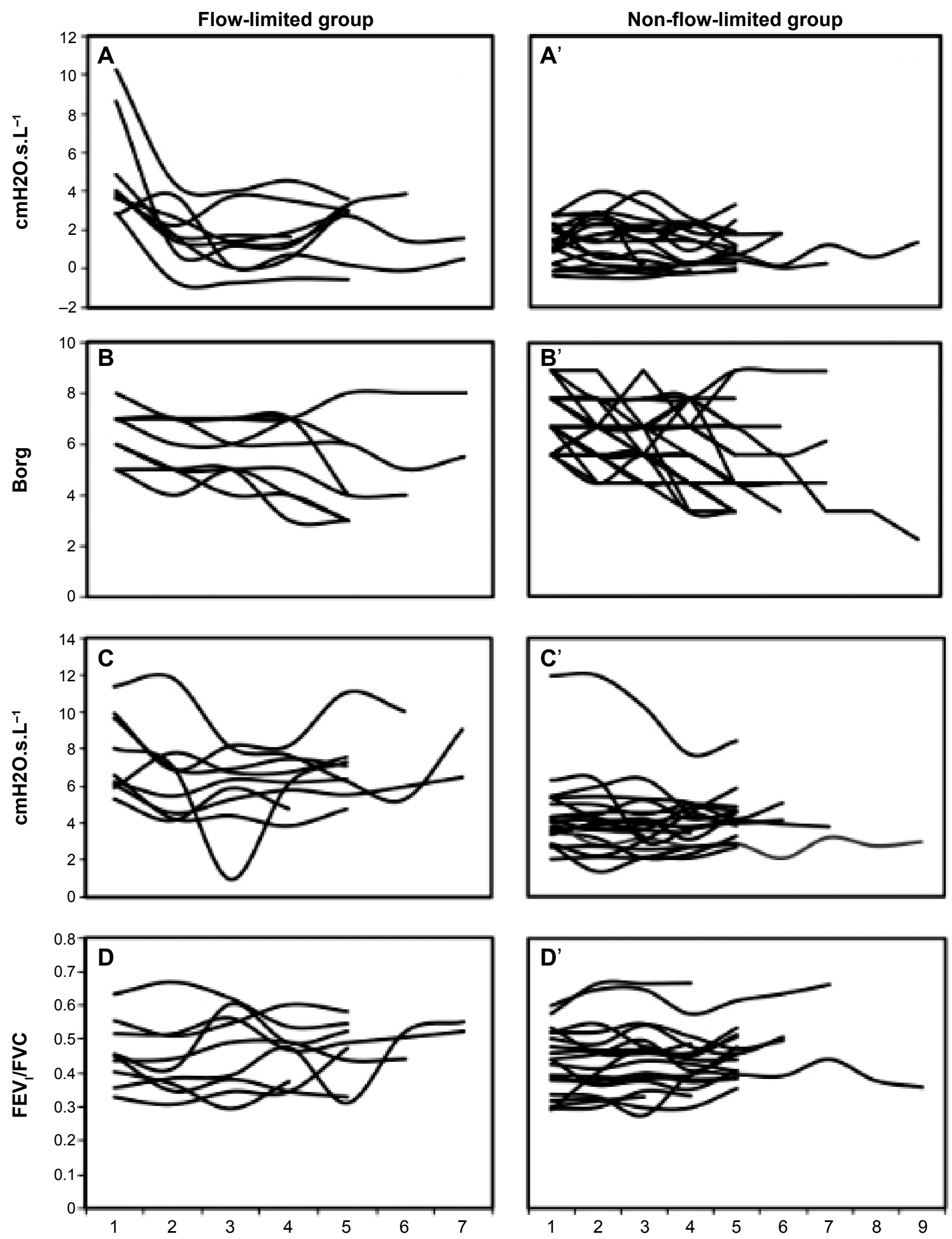

Figure I Daily tracking in subjects with and without flow-limited breathing at recruitment. Notes: (A and A') EFL index; (B and B') symptom (Borg) score; (C and C') $\operatorname{Rrs}_{\text {insp }}$; (D and D') FEV, /FVC.

Abbreviations: EFL, expiratory flow limitation (defined by EFL index $>2.8 \mathrm{cmH}_{2} \mathrm{O} \cdot \mathrm{s} \cdot \mathrm{L}^{-1}$ ); Rrs , mean respiratory system resistance during inspiration; FEV, forced expiratory volume in I second; FVC, forced vital capacity; Xrs, mean respiratory system reactance; $\Delta$ Xrs, Xrs during inspiration - Xrs during expiration. 
Table 3 Mixed-effect analysis. Predictors of symptom (Borg) scores during recovery from COPD exacerbations

\begin{tabular}{|c|c|c|c|c|}
\hline Outcome & Predictor & Units & $\beta$-coefficient $( \pm$ SE) & $P$ \\
\hline \multicolumn{5}{|c|}{ EFL at admission } \\
\hline \multirow[t]{4}{*}{ Borg score } & $\mathrm{FEV}_{1} / \mathrm{FVC}$ & & $-1.56(1.14)$ & 0.2 \\
\hline & FVC & $\mathrm{L}$ & $-0.20(0.47)$ & 0.7 \\
\hline & $\operatorname{Rrs}_{\text {insp }}$ & $\mathrm{cmH}_{2} \mathrm{O} \cdot \mathrm{s} \cdot \mathrm{L}^{-1}$ & $-0.24(0.11)$ & 0.04 \\
\hline & $\Delta \mathrm{Xrs}$ & $\mathrm{cmH}_{2} \mathrm{O} \cdot \mathrm{s} \cdot \mathrm{L}^{-1}$ & $0.26(0.09)$ & 0.01 \\
\hline \multicolumn{5}{|c|}{ No EFL at admission } \\
\hline \multirow[t]{4}{*}{ Borg score } & $\mathrm{FEV}_{1} / \mathrm{FVC}$ & & $-3.79(1.76)$ & 0.03 \\
\hline & FVC & $\mathrm{L}$ & $-0.33(0.38)$ & 0.4 \\
\hline & $\operatorname{Rrs}_{\text {insp }}$ & $\mathrm{cmH}_{2} \mathrm{O} \cdot \mathrm{s} \cdot \mathrm{L}^{-1}$ & $0.08(0.09)$ & 0.4 \\
\hline & $\Delta \mathrm{Xrs}$ & $\mathrm{cmH}_{2} \mathrm{O} \cdot \mathrm{s} \cdot \mathrm{L}^{-1}$ & $-0.07(0.17)$ & 0.7 \\
\hline
\end{tabular}

Notes: Separate models were run for each group. All predictors entered into the models are shown. Effect sizes of significant predictors are independent of the other predictors in the model.

Abbreviations: SE, standard error; EFL, expiratory flow limitation (defined by EFL index $>2.8 \mathrm{cmH}_{2} \mathrm{O} \cdot \mathrm{s} \cdot \mathrm{L}^{-1}$ ); FEV , forced expiratory volume in I second; FVC, forced vital capacity; $\operatorname{Rrs}_{\text {insp }}$, mean respiratory system resistance during inspiration; Xrs, mean respiratory system reactance; $\Delta$ Xrs, $\mathrm{Xrs}$ during inspiration - Xrs during expiration; COPD, Chronic obstructive pulmonary disease.

significant determinant of improved dyspnea during recovery in hospital.

Changes in $\operatorname{Rrs}_{\text {insp }}$ were inversely related to changes in Borg scores, whereby an increase in $\operatorname{Rrs}_{\text {insp }}$ was associated with a greater improvement in Borg score. This apparently paradoxical relationship may be explained by possible changes in end-expiratory lung volume, since Rrs is hyperbolically related to lung volume. ${ }^{18}$ Therefore, if improvement in dyspnea were associated with an improvement in hyperinflation, ${ }^{4}$ ie, an increase in inspiratory capacity, then there may have been an associated increase in $\mathrm{Rrs}_{\text {insp }}$. However, inspiratory capacity is a difficult measurement, and even harder when subjects are acutely unwell, and was not measured in this study.

The use of a mixed-effect analysis in this study allowed the inclusion of all the longitudinal data, ie, daily data from every patient, irrespective of their hospital stay. This provided a robust way of analyzing longitudinal associations between the variables. Previous studies examined correlations between changes in measured variables from one relatively fixed interval to another, ${ }^{4,5}$ and did not report significant relationships between changes in physiological parameters (including hyperinflation) and Borg scores during recovery from exacerbations over 6 weeks from hospital admission. ${ }^{4,5}$ We did not find any significant differences in the length of stay between the groups, but this could have been due to the small number of patients in the group with EFL. The decision to discharge was based on the clinical assessment of the patients' usual medical team, and it is unlikely that there were any systematic differences between groups in terms of decision to discharge. Contrary to the previously mentioned studies ${ }^{4,5}$ spirometry did not improve in this cohort. This lack of treatment response during recovery from an exacerbation may have been due to the presence of more severe obstruction at baseline in this patient group $\left(\mathrm{FEV}_{1} 31 \%\right.$ predicted) compared to others (FEV $47 \%{ }^{4}$ and $43 \% 5$ predicted).

This study has some limitations. The small sample size has already been mentioned. It is possible in this uncontrolled observational study that unrecognized confounding factors other than EFL could have also contributed to the significant association between EFL and hospital length of stay. The lack of lung-volume measurements as a marker of hyperinflation over the course of the admission limited our ability to interpret the relationship between flow limitation, Rrs, and Borg scores. However, accurate measurement of lung volumes is difficult in these patients with significant dyspnea and tachypnea. The current study did not include measures of airway or systemic inflammation to examine possible mechanisms underlying changes in EFL index values, reactance, and symptoms during recovery. Repeating this study with more detailed markers would therefore be worthwhile.

In conclusion, flow-limited breathing during acute COPD exacerbations occurs in some patients admitted to hospital, and resolves in approximately half of those during recovery. The reduction in EFL index values during recovery is associated with an improvement in symptoms in COPD patients who present to hospital with flow-limited breathing. Further work is required to determine whether monitoring EFL during recovery can be used to guide or titrate treatment with the aim of reducing the duration of hospital admission and improving clinical outcomes. 


\section{Acknowledgments}

Thank you to Mr Gunnar Unger and Mr Tom Li (Woolcock Institute of Medical Research) for technical support and the patients and staff at West China Hospital. This study was funded by the Cooperative Research Centre for Asthma and Airways (Australia), an NHMRC Practitioner Fellowship (GGK), and an unrestricted grant by Boehringer Ingelheim (CMS).

\section{Author contributions}

$\mathrm{KJ}$ and $\mathrm{NJB}$ contributed to data analysis, data interpretation and writing of manuscript. ST, FQW, PC contributed to study design, data collection and writing of manuscript. CD contributed to data analysis and writing of manuscript. NB, CMS and GGK contributed to study design, data interpretation and writing of manuscript. CSF contributed to data interpretation and writing of manuscript. All authors were responsible for critically revising the paper and agree to be accountable for all aspects of the work.

\section{Disclosure}

The authors report no conflicts of interest in this work.

\section{References}

1. Aarli BB, Calverley PM, Jensen RL, Eagan TM, Bakke PS, Hardie JA. Variability of within-breath reactance in COPD patients and its association with dyspnoea. Eur Respir J. Epub 2014 Oct 30.

2. O’Donnell DE, Parker CM. COPD exacerbations. 3: Pathophysiology. Thorax. 2006;61(4):354-361.

3. Aaron SD, Donaldson GC, Whitmore GA, Hurst JR, Ramsay T, Wedzicha JA. Time course and pattern of COPD exacerbation onset. Thorax. 2012;67(3):238-243.

4. Stevenson NJ, Walker PP, Costello RW, Calverley PM. Lung mechanics and dyspnea during exacerbations of chronic obstructive pulmonary disease. Am J Respir Crit Care Med. 2005;172(12):1510-1516.
5. Johnson MK, Birch M, Carter R, Kinsella J, Stevenson RD. Measurement of physiological recovery from exacerbation of chronic obstructive pulmonary disease using within-breath forced oscillometry. Thorax. 2007;62(4):299-306.

6. Dellaca RL, Santus P, Aliverti A, et al. Detection of expiratory flow limitation in COPD using the forced oscillation technique. Eur Respir J. 2004;23(2):232-240.

7. Dellacà RL, Rotger M, Aliverti A, Navajas D, Pedotti A, Farré R. Noninvasive detection of expiratory flow limitation in COPD patients during nasal CPAP. Eur Respir J. 2006;27(5):983-991.

8. Dellacà RL, Pompilio PP, Walker PP, Duffy N, Pedotti A, Calverley PM. Effect of bronchodilation on expiratory flow limitation and resting lung mechanics in COPD. Eur Respir J. 2009;33(6):1329-1337.

9. Eltayara L, Becklake MR, Volta CA, Milic-Emili J. Relationship between chronic dyspnea and expiratory flow limitation in patients with chronic obstructive pulmonary disease. Am J Respir Crit Care Med. 1996;154(6 Pt 1):1726-1734.

10. GOLD (Global initiative for chronic Obstructive Lung Disease). Global Strategy for Diagnosis, Management and Prevention of COPD Bethesda (MD): GOLD; 2011.

11. Burdon JG, Juniper EF, Killian KJ, Hargreave FE, Campbell EJ. The perception of breathlessness in asthma. Am Rev Respir Dis. 1982;126(5):825-828.

12. Miller MR, Hankinson J, Brusasco V, et al. Standardisation of spirometry. Eur Respir J. 2005;26(2):319-338.

13. Hankinson JL, Odencrantz JR, Fedan KB. Spirometric reference values from a sample of the general U.S. population. Am J Respir Crit Care Med. 1999;159(1):179-187.

14. Thorpe CW, Salome CM, Berend N, King GG. Modeling airway resistance dynamics after tidal and deep inspirations. J Appl Physiol (1985). 2004;97(5):1643-1653.

15. Robinson PD, Turner M, Brown NJ, et al. Procedures to improve the repeatability of forced oscillation measurements in school-aged children. Respir Physiol Neurobiol. 2011;177(2):199-206.

16. Parker CM, Voduc N, Aaron SD, Webb KA, O’Donnell DE. Physiological changes during symptom recovery from moderate exacerbations of COPD. Eur Respir J. 2005;26(3):420-428.

17. Perera WR, Hurst JR, Wilkinson TM, et al. Inflammatory changes, recovery and recurrence at COPD exacerbation. Eur Respir J 2007;29(3):527-534.

18. Briscoe WA, Dubois AB. The relationship between airway resistance, airway conductance and lung volume in subjects of different age and body size. J Clin Invest. 1958;39(9):1279-1285.
International Journal of COPD

\section{Publish your work in this journal}

The International Journal of COPD is an international, peer-reviewed journal of therapeutics and pharmacology focusing on concise rapid reporting of clinical studies and reviews in COPD. Special focus is given to the pathophysiological processes underlying the disease, intervention programs, patient focused education, and self management protocols.

\section{Dovepress}

This journal is indexed on PubMed Central, MedLine and CAS. The manuscript management system is completely online and includes a very quick and fair peer-review system, which is all easy to use. Visit http://www.dovepress.com/testimonials.php to read real quotes from published authors. 